Revue d'histoire du XIXe siècle

Société d'histoire de la révolution de 1848 et des

révolutions du XIXe siècle

Religion, politique et culture au XIXe siècle

\title{
Sophie Kovalevskaïa, Une nihiliste, traduit du russe par Michel Niqueux, Paris, Éditions Phebus, 2004, $175 \mathrm{p}$.
}

Nicole Edelman

\section{CpenEdition}

Édition électronique

URL : http://journals.openedition.org/rh19/651

DOI : 10.4000/rh19.651

ISSN : $1777-5329$

Éditeur

La Société de 1848

Édition imprimée

Date de publication : 1 juin 2004

Pagination : 220

ISSN : 1265-1354

\section{Référence électronique}

Nicole Edelman, «Sophie Kovalevskaïa, Une nihiliste, traduit du russe par Michel Niqueux, Paris,

Éditions Phebus, 2004, 175 p. », Revue d'histoire du XIXe siècle [En ligne], 28 | 2004, mis en ligne le 19 juin 2005, consulté le 22 septembre 2020. URL : http://journals.openedition.org/rh19/651 ; DOI :

https://doi.org/10.4000/rh19.651

Ce document a été généré automatiquement le 22 septembre 2020

Tous droits réservés 


\title{
Sophie Kovalevskaïa, Une nihiliste, traduit du russe par Michel Niqueux, Paris, Éditions Phebus, 2004, 175 p.
}

\author{
Nicole Edelman
}

1 Ce roman autobiographique nous conduit par des tours et des détours jusqu'au bout d'une sorte d'engagement plus mystique que politique, celui de Vera (Foi), jeune femme, fille d'un propriétaire terrien russe qui reçoit une bonne éducation, ouverte et libre. Le roman s'inscrit dans la Russie des années 1860 : après la mort du tsar Nicolas $\mathrm{I}^{\mathrm{er}}$, le tsar Alexandre abolit le servage et Vera prend la décision d'éduquer les petits paysans en se faisant institutrice. Elle découvre ainsi le malheur des hommes et la tragédie des pauvres et des opprimés. Convaincue par les idées révolutionnaires des premiers nihilistes à travers rencontres et dialogues, elle part à Saint-Pétersbourg où elle espère pouvoir agir. Déçue, elle prendra le train pour la Sibérie pour rejoindre un condamné politique au bagne. Elle a épousé cet homme en prison sans même le connaître, l'ayant tout juste vu et entendu à son procès; mais, Véra, princesse Barantsov, a enfin trouvé « une cause » à laquelle consacrer sa vie.

2 Roman paradoxal, Une nihiliste allie clichés romantiques (on y pleure beaucoup) et tensions du déroulement de l'action. S'il n'est pas un texte politique, il est néanmoins une critique sociale et un regard sur soi de l'auteure. La vie de Sophie Kovalevskaïa (1850-1891) est en effet celle d'une femme exceptionnelle : intellectuelle, scientifique, militante politique (elle participe à la Commune de Paris avec sa sœur) que Michel Niqueux nous fait découvrir dans une longue introduction. 